\title{
Peningkatan Hasil Belajar Ilmu Pengetahuan Alam Peserta Didik Melalui Media Model Dengan Metode Inkuiri Di Kelas V SD Negeri 04 Payakumbuh Tahun 2019 / 2020
}

\author{
Vivi Rezkia \\ SD Negeri 04 Payakumbuh \\ Jl. Ade Irma Suryani No.13, Labuh Baru, Kota Payakumbuh, Sumatera Barat, Indonesia \\ vivi_rezkia@gmail.com
}

\begin{abstract}
This study aims to improve student learning outcomes in class VC SD Negeri 04 Payakumbuh through a media model using the inquiry method. This type of research is classroom action research (CAR). The subjects of this study were all VC class students of SD Negeri 04 Payakumbuh in the 2019/2020 school year, totaling 35 people. The data obtained comes from student data, teachers, and documentation. The data collection procedure used observation instruments, field notes, tests, and documentation. The results showed that the media model with the inquiry method could improve student learning outcomes in science subjects for class VC SD Negeri 04 Payakumbuh. This is evidenced by the average value from the initial conditions of 62 , in the first cycle it rose to 68.57, in the second cycle it became 76.28 and in the third cycle it reached 84 .
\end{abstract}

Keywords: Science Learning Outcomes, Media Models, Inquiry Methods

\begin{abstract}
Abstrak
Penelitian ini bertujuan untuk meningkatkan hasil belajar siswa kelas VC SD Negeri 04 Payakumbuh melalui media model dengan menggunakan metode inkuiri. Jenis penelitian ini adalah penelitian tindakan kelas (PTK). Subjek penelitian ini adalah seluruh siswa kelas VC SD Negeri 04 Payakumbuh pada tahun pelajaran 2019/2020 yang berjumlah 35 orang. Data yang diperoleh bersumber dari data siswa, guru, dan dokumentasi. Prosedur pengumpulan data menggunakan instrumen pengamatan, catatan lapangan, tes dan dokumentasi. Hasil penelitian menunjukkan bahwa melalui media model dengan metode inkuiri dapat meningkatkan hasil belajar siswa pada mata pelajaran IPA kelas VC SD Negeri 04 Payakumbuh. Hal ini dibuktikan dengan rata-rata nilai dari kondisi awal 62, pada siklus I naik menjadi 68,57, pada siklus II menjadi 76,28 dan pada siklus 3 mencapai 84.
\end{abstract}

Kata kunci: Hasil Belajar IPA, Media Model, Metode Inkuiri

Copyright (c) 2021 Vivi Rezkia

Corresponding author: Vivi Rezkia

Email Address: vivi_rezkia @ gmail.com (Jl. Ade Irma Suryani No.13, Labuh Baru, Kota Payakumbuh)

Received 09 May 2021, Accepted 02 July 2021, Published 03 July 2021

\section{PENDAHULUAN}

Pendidikan merupakan suatu usaha yang diselenggarakan untuk membangun manusia Indonesia seutuhnya yang berkualitas dan menjadi kebanggaan bangsa dan Negara. Berbagai upaya telah dilakukan pemerintah dalam rangka pencapaian tujuan Pendidikan Nasional seperti yang tertuang dalam Undang Undang Sistem Pendidikan nasional No.20 tahun 2003 pasal 3 yang menyatakan bahwa Pendidikan Nasional berfungsi mengembangkan kemampuan dan membentuk watak serta peradaban bangsa yang bermartabat dalam rangka mencerdaskan kehidupan bangsa,bertujuan untuk berkembangnya potensi peserta didik agar menjadi manusia yang beriman dan bertaqwa kepada Tuhan Yang Maha Esa, berakhlak mulia, sehat, berilmu, cakap, kreatif, mandiri, dan menjadi warga negara yang demokratis dan bertanggung jawab. 
Salah satu usaha untuk mewujudkan tujuan Pendidikan Nasional diatas adalah melalui kegiatan pendidikan baik pendidikan formal, informal dan non formal. Inti dari proses pendidikan adalah proses belajar mengajar. Ilmu pengetahuan alam (IPA) tidak dapat diajarkan dengan metode ceramah, melainkan melalui pembelajaran siswa aktif. Dalam Pembelajaran IPA seorang guru yang profesional sejati memiliki perencanaan dan persiapan serta indikator yang akan dicapai dalam PBM sehingga tujuan pembelajaran dapat tercapai sesuai yang diharapkan. Tujuan pendidikan IPA di Sekolah Dasar (SD) hendaknya lebih menekankan pada pemikiran kecakapan proses atau kecakapan generik dibandingkan penggunaan syarat yang harus dimiliki siswa, agar siswa dapat mempelajari bidang studi lainnya sesuai dngan minatnya. Kecakapan generik yang dimiliki siswa SD akan berfungsi menjadi alat bagi mereka untuk menggali konsep-konsep keilmuan yang diminatinya pada jenjang pendidikan yang berikutnya.

Penentuan keberhasilan siswa dapat dilihat dari proses pembelajaran yang dinyatakan dengan nilai. Pada pembelajaran tentang IPA ini terlihat bahwa hasil belajar siswa masih banyak memperoleh nilai dibawah 80. Pada semester 1 tahun pelajaran 2019-2020, pembelajaran tentang IPA di kelas VC menunjukkan rendahnya tingkat penguasaan siswa terhadap materi pelajaran. Dari 35 orang siswa kelas 5 hanya 15 orang yang mencapai tingkat penguasaan materi $80 \%$ keatas, di antaranya yang memperoleh nilai 80 sebanyak 7 orang, yang memperoleh nilai 90 sebanyak 3 orang, yang memperolah nilai 100 sebanyak 5 orang, sehingga rata-rata kelas baru mencapai nilai 62 .

Dari latar belakang diatas Penelitian ini bertujuan untuk mendapatkan data dan informasi tentang hasil belajar siswa terhadap materi pelajaran Ilmu Pengetahuan Alam tentang system pernapasan manusia di kelas VC SDN 04 Payakumbuh melalui media/model.

Belajar adalah suatu atau serangkaian aktifitas yang dialami seseorang melalui interaksinya dengan lingkungan. Interaksi tersebut mungkin berawal dari faktor yang berasal dalam atau luar diri sendiri. Dengan terjadinya interaksi dengan lingkungan akan menyebabkan munculnya proses penghayatan dalam diri individu dan akan memungkinkan terjadinya perubahan pada diri siswa tersebut.

Mukhtar (2015: 8) menyatakan bahwa pengertian belajar secara psikologis merupakan suatu proses perubahan yaitu perubahan tingkah laku sebagai hasil dari interaksi dengan lingkungannya dalam memenuhi kebutuhan hidupnya. Perubahan-perubahan tersebut akan nyata dalam aspek tingkah laku. Menurut Sardiman A.M ( $2016: 21$ ) Belajar adalah berubah dalam hal ini yang di maksudkan belajar berarti usaha mengubah tingkah laku. Jadi belajar akan membawa suatu perubahan pada individuindividu yang belajar. Dari pendapat para ahli dan uraian di atas maka dapat disimpulkan belajar adalah perubahan dalam diri seseorang yang dapat dinyatakan dengan adanya penguasaan pola sambutan yang baru berupa pemahaman, keterampilan dan sikap sebagai hasil proses hasil pengalaman yang dialami.

Hasil belajar menurut Bloom (Supriono, 2009:6-7) mencakup kemampuan kognitif, afektif dan psikomotorik. Domain kognitif adalah knowledge (pengetahuan, ingatan). Comprehension (pemahaman, menjelaskan, meringkas, contoh), application (menerapkan), analisis (menguraikan, 
menentukan hubungan), syinthesis (mengorganisasikan, merencanakan, membentuk bangunan baru), dan evaluation (menilai). Domain afektif adalah sikap menerima, memberikan respon, nilai, organisasi, karakterisasi. Domain psikomotor meliputi keterampilan produktif, teknik, fisik, social, manajerial, dan intelektual.

Menurut Jihad dan Haris (2012:14) pengertian hasil belajar merupakan pencapaian bentuk perubahan perilaku yang cenderung menetap dari rana kognitif, afektif, dan psikomotor dari proses belajar yang dilakukan dalam tertentu. Dapat disimpulkan bahwa pengertian hasil belajar adalah kemampuan yang dimiliki siswa berupa prestasi belajar secara keseluruhan bak yang menyangkut ranah kognitif, afektif maaupun psikomotorik.

Menurut H.W Flowler dalam Trianto, (2010:136) menyatakan bahwa IPA sebagai pengetahuan yang sistematis dan dirumuskan yang berhubungan dengan gejala-gejala kebendaan dan didasarkan terutama atas pengamatan dan deduksi. Susanto (2015: 167) memberikan pengertian tentang sains atau IPA yaitu usaha manusia dalam memahami alam semesta melalui pengamatan yang tepat pada sasaran, serta menggunakan prosedur, dan dijelaskan dengan penalaran sehingga mendapatkan suatu kesimpulan.

Pengertian IPA disampaikan lebih luas oleh Trianto (2011: 136) yaitu sekumpulan teori yang sistematis, penerapannya secara umum terbatas pada gejala-gejala alam, lahir, dan berkembang melalui metode ilmiah seperti observasi dan eksperimen serta menuntut sikap ilmiah seperti rasa ingin tahu, terbuka, jujur, dan sebagainya.Berdasarkan dari beberapa pendapat di atas maka dapat disimpulkan bahwa IPA merupakan pengetahuan dari hasil kegiatan manusia yang diperoleh dengan menggunakan langkah-langkah ilmiah yang berupa metode ilmiah dan didapatkan dari hasil eksperimen atau observasi yang bersifat umum sehingga akan terus disempurnakan dan sains merupakan produk dan proses yang tidak dapat dipisahkan.

Menurut Syaiful Bahri Djamarah: Media adalah alat bantu apa saja yang dapat dijadikan sebagai penyalur pesan guna mencapai tujuan. Menurut Schram: Media adalah teknologi pembawa pesan yang dapat dimanfaatkan untuk keperluan pembelajaran.

Menurut National Education Asociation (NEA): Media adalah sarana komunikasi dalam bentuk cetak maupun audio visual, termasuk teknologi perangkat kerasnya. Menurut Briggs: Media adalah alat untuk memberikan perangsang bagi siswa supaya terjadi proses belajar. Menurut Gagne: Media adalah berbagai jenis komponen dalam lingkungan siswa yang dapat merangsang siswa untuk belajar. Media dikatakan pula sebagai sebagai segala bentuk dan saluran yang digunakan orang untuk menyalurkan pesan/informasi. Kata segala memberi makna bahwa media tidak terbatas pada jenis media yang dirancang secara khusus untuk mencapai tujuan tertentu tetapi keberadaanya dapat mempermudah atau memperjelas pemahaman siswa terhadap materi atau pesan tertentu, jadi dalam bentuk apapun apabila dapat menyalurkan pesan dapat disebut sebagai media. (Prasetya, 2015). Dari beberapa penjelasan para ahli diatas dapat disimpulkan bahwa media adalah saluran atau jembatan dari pesa-pesan pembelajaran 
yang disampaikan oleh guru kepada siswa dengan maksud agar pesan-pesan tersebut dapat diserap dengan cepat sesuai dengan tujuannya.

Menurut Sri Anitah, W media model atau media tiga dimensi merupakan tiruan dari beberapa objek nyata, seperti objek yang terlalu besar, objek yang terlalu jauh objek yang terlalu kecil, objek yang terlalu mahal, objek yang jarang di temukan atau objek yang terlalu rumit untuk dibawa kedalam kelas dan sulit di pelajari siswa wujud aslinya. Roestiah (2008:75) menyatakan bahwa Inkuiri adalah istilah dalam bahasa Inggris, ini merupakan suatu teknik atau cara yang digunakan guru untuk mengajar didepan kelas. Adapun pelaksanaannya sebagai berikut: guru membagi tugas meneliti suatu masalah ke kelas siswa dibagi menjadi beberapa kelompok dan masing-masing kelompok mendapatkan tugas tertentu yang harus dikerjakan. Kemudian mereka mempelajari, meneliti, dan membahas tugasnya didalam kelompok. Setelah hasil kerja mereka dalam kelompok didiskusikan, kemudian dibuat laporan yang tersusun dengan baik.

Wina (2008:196) mengungkapkan" metode inkuiri didasari oleh teori belajar kotruktivistik, dimana pengetahuan itu akan bermakna manakala dicari dan ditemukan sendiri oleh siswa". Hal senada juga diungkapkan oleh Kunandar (2007: 309) yang mengatakan bahwa "Pengetahuan yang diperoleh siswa diharapkan bukan hasil mengingat seperangkat fakta-fakta, tetapi hasil dari menemukan sendiri”. Dengan demikian, dalam proses perencanaan guru bukanlah mempersiapkan sejumlah materi yang harus dihafal, akan tetapi merancang pembelajaran yang memungkinkan siswa menemukan sendiri materi yang harus dihafal, akan tetapi merancang pembelajaran yang memungkinkan siswa menemukan sendiri materi yang harus dipahaminya.

Nofilah juga menjelaskan (2009:2) "Metode inkuiri adalah cara penyajian pembelajaran yag memberikan kesempatan kepada siswa untuk menemukan informasi dengan aktif tapa bantuan guru". Ini berarti metode inkuiri menerapkan serangkaian proses pembelajaran yang menekankan pada proses berpikir secara kritis dan analitis untuk mencari dan menemukan sendiri jawaban dari suatu masalah yang dipertanyakan.

Berdasarkan uraian di atas guru membagi tugas meneliti sesuatu masalah, siswa dibagi menjadi beberapa kelompok, dan tugas yang diberikan pada masing-masing kelompok berbeda, mereka mempelajari, meneliti, dan membahas tugas yang akan diberiakan guru dalam kelompoknya kemudian hasil kelompoknya didiskusikan dan dibuat laporan, guru di sini sebagai pengamat dalam diskusi kelompok siswa.

\section{METODE}

\section{Setting Penelitian}

Jenis penelitian yang digunakan peneliti adalah Penelitian Tindakan Kelas (PTK). Penelitian ini dilaksanakan di SDN 04 Payakumbuh yang terletak di jalan Ade Irma Suryani no 17 kelurahan Koto Kociak Kubu Tapak Rajo Kota Payakumbuh provinsi sumatera barat. Penelitian ini dilaksanakan selama dua belas hari yaitu pada hari selasa tanggal 13 Agustus 2019 sampai hari Jum'at tanggal 23 
Agustus 2019. Subjek dalam penelitian ini adalah peserta didik kelas VC SD Negeri 04 Payakumbuh yang berjumlah 35 orang peserta didik, terdiri dari 16 orang peserta didik laki-laki dan 19 orang peserta didik perempuan. Prosedur penelitian terdiri dari tiga siklus dengan empat tahap penelitian mulai dari perencanaan, pelaksanaan, observasi dan refleksi. Teknik pengumpulan data yang digunakan dalam penelitian ini adalah menggunakan teknik catatan lapangan, lembar kerja peserta didik, tes tertulis, observasi, dan dokumentasi. Teknik analisis data dengan cara teknik persentase.

\section{HASIL DAN DISKUSI}

\section{Siklus I}

a. Perencanaan

Pada tahap perncanaan kegiatan yang dilaksanakan adalah: Mengidentifikasi masalah. Berdiskusi dengan supervisor. Membuat rencana pembelajaran. Menyediakan perangkat pembelajaran meliputi alat, sumber, dan sarana pembelajaran. Merancang alat evaluasi. Membuat format penilaian untuk mendata hasil belajar siswa.

b. Pelaksanaan

Pertemuan pertama dilaksanakan pada tanggal 16 Agustus 2019 dengan materi Organ Pernapasan Manusia. Pada tahap pelaksanaan terdiri dari tiga tahapan yaitu kegiatan awal, kegiatan inti dan kegiatan penutup.

c. Observasi

Data pelaksanaan tindakan penelitian diperoleh berupa nilai hasil belajar siswa. Hasil belajar ini berasal dari tes formatif yang dilakukan pada akhir kegiatan pembelajaran. Berdasarkan hasil tes siswa dianalisa pencapaian rata-rata serta persentase ketuntasan yang diperoleh pada setiap siklus. Hasil observasi pengamatan terhadap guru dan siswa dilakukan pada setiap siklus, juga menentukan keberhasilan penelitian ini. Berdasarkan hasil observasi didapat bahwa faktor siswa dan guru sangat berpengaruh pada keberhasilan penelitian ini. Untuk mengetahui hasil belajar siswa setelah dilaksanakan perbaikan proses pembelajaraan, siswa mengerjakan soal tes. Berdasarkan hasil tes penulis memperoleh data siklus pertama berupa nilai yang tergambar pada table berikut:

Tabel 1. Hasil belajar Siswa pada Siklus 1

\begin{tabular}{|c|c|c|c|c|}
\hline No & Nama Siswa & KD 3.2 & Tuntas & Tidak Tuntas \\
\hline 1 & AR & 70 & & V \\
\hline 2 & ASL & 70 & & V \\
\hline 3 & ALF & 50 & & V \\
\hline 4 & ARD & 70 & & V \\
\hline 5 & ATF & 80 & & V \\
\hline 6 & AZR & 50 & & V \\
\hline 7 & CRY & 70 & & V \\
\hline 8 & DNS & 100 & V & \\
\hline 9 & FZH & 40 & & V \\
\hline
\end{tabular}




\begin{tabular}{|c|c|c|c|c|}
\hline 10 & FRD & 100 & $\mathrm{~V}$ & \\
\hline 11 & FTR & 100 & $\mathrm{~V}$ & \\
\hline 12 & FTY & 90 & $\mathrm{~V}$ & \\
\hline 13 & FTH & 90 & $\mathrm{~V}$ & \\
\hline 14 & FZI & 70 & & $\mathrm{~V}$ \\
\hline 15 & GRN & 80 & $\mathrm{~V}$ & \\
\hline 16 & HBL & 50 & & $\mathrm{~V}$ \\
\hline 17 & $\mathrm{HNF}$ & 60 & & $\mathrm{~V}$ \\
\hline 18 & IBR & 100 & $\mathrm{~V}$ & \\
\hline 19 & IHSN & 60 & & $\mathrm{~V}$ \\
\hline 20 & ARS & 100 & $\mathrm{~V}$ & \\
\hline 21 & KRN & 100 & $\mathrm{~V}$ & \\
\hline 22 & $\mathrm{AQL}$ & 80 & $\mathrm{~V}$ & \\
\hline 23 & MLW & 80 & $\mathrm{~V}$ & \\
\hline 24 & MTR & 40 & & $\mathrm{~V}$ \\
\hline 25 & MDF & 40 & & $\mathrm{~V}$ \\
\hline 26 & MHFZ & 40 & & $\mathrm{~V}$ \\
\hline 27 & MGL & 70 & & $\mathrm{~V}$ \\
\hline 28 & NBL & 40 & & $\mathrm{~V}$ \\
\hline 29 & NFL & 40 & & $\mathrm{~V}$ \\
\hline 30 & OLV & 60 & & $\mathrm{~V}$ \\
\hline 31 & RVN & 70 & & $\mathrm{~V}$ \\
\hline 32 & REYHN & 80 & $\mathrm{~V}$ & \\
\hline 33 & RHY & 60 & & $\mathrm{~V}$ \\
\hline 34 & SHVR & 50 & & $\mathrm{~V}$ \\
\hline \multirow[t]{3}{*}{35} & SHNT & 90 & $\mathrm{~V}$ & \\
\hline & Jumlah & 2400 & & \\
\hline & Rata - Rata & 68,57 & & \\
\hline
\end{tabular}

Dari table hasil belajar siswa diatas dapat dianalisa selama guru menggunakan media model dengan metode inkuiri di peroleh nilai rata - rata 68, 57.

Tabel 2. Rentangan Nilai Yang Diperoleh Siswa Siklus I

\begin{tabular}{|c|c|}
\hline Nilai & Hasil Yang Diperoleh \\
\hline $0-60$ & 15 \\
\hline $61-70$ & 4 \\
\hline $71-80$ & 7 \\
\hline $81-90$ & 3 \\
\hline $91-100$ & 6 \\
\hline
\end{tabular}

\section{d. Refleksi}

Setelah penelitian selesai dilaksanakan, guru bersama teman kolaborasi yakninya Ibu Zuharnelhas, S.Pd. SD berdiskusi untuk mmembicarakan hal - hal yang ditemukan saat observasi, baik yang positif maupun yang negative serta catatan - catatan penting yang harus disampaikan, diantaranya: Siswa belum menunjukkan kegembiraan dalam pembelajaran. Dalam proses pembelajaran siswa belum 
berani memberikan jawaban dari pertanyaan yang diajukan temannya. Siswa juga belum berani memberikan jawaban dari pertanyaan yang diajukan guru. Siswa belum aktif dalam kelompok. Siswa belum mampu bekerjasama dalam kelompoknya. Guru belum mengajukan pertanyaan menantang. Guru belum mengaitkan materi pembelajaran sekarang dengan pengalaman peserta didikn atau pembelajaran sebelumnya. Guru belum mengaitkan materi dengan pengetahuan siswa yang relevan, perkembangan iptek, dan kehidupan nyata. Guru belum menyajikan materi secara sistematis (mudah ke sulit, dari konkrit ke abstrak. Hasil diskusi dengan teman kolaborasi akan dijadikan sebagai bahan untuk perbaikan tindakan pada siklus berikutnya.

\section{Siklus II}

a. Perencanaan

Pada tahap ini peneliti mempersiapkan perangkat pembelajaran yang terdiri dari rencana pelajaran, LKPD dan alat alat pengajaran yang mendukung.

b. Pelaksanaan

Pertemuan siklus kedua dilaksanakan pada tanggal 22 Agustus 2019 dengan materi Proses Pernapasan Manusia. Pada tahap pelaksanaan terdiri dari tiga tahapan yaitu kegiatan awal, kegiatan inti dan kegiatan penutup.

c. Observasi

Data pelaksanaan tindakan penelitian diperoleh berupa nilai hasil belajar siswa. Hasil belajar ini berasal dari tes formatif yang dilakukan pada akhir kegiatan pembelajaran. Berdasarkan hasil tes siswa dianalisa pencapaian rata-rata serta persentase ketuntasan yang diperoleh pada setiap siklus. Hasil observasi pengamatan terhadap guru dan siswa dilakukan pada setiap siklus, juga menentukan keberhasilan penelitian ini. Berdasarkan hasil observasi didapat bahwa faktor siswa dan guru sangat berpengaruh pada keberhasilan penelitian ini. Untuk mengetahui hasil belajar siswa setelah dilaksanakan perbaikan proses pembelajaraan, siswa mengerjakan soal tes. Berdasarkan hasil tes penulis memperoleh data siklus kedua berupa nilai yang tergambar pada table berikut:

Tabel 3. Nilai Siswa Pada Siklus II

\begin{tabular}{|r|l|c|c|c|}
\hline No & Nama Siswa & KD 3.2 & Tuntas & Tidak Tuntas \\
\hline 1 & AR & 70 & & $\mathrm{~V}$ \\
\hline 2 & ASL & 80 & $\mathrm{~V}$ & \\
\hline 3 & ALF & 60 & & $\mathrm{~V}$ \\
\hline 4 & ARD & 80 & $\mathrm{~V}$ & \\
\hline 5 & ATF & 80 & $\mathrm{~V}$ & \\
\hline 6 & AZR & 60 & & $\mathrm{~V}$ \\
\hline 7 & CRY & 70 & & $\mathrm{~V}$ \\
\hline 8 & DNS & 100 & $\mathrm{~V}$ & \\
\hline 9 & FZH & 50 & & $\mathrm{~V}$ \\
\hline 10 & FRD & 100 & $\mathrm{~V}$ & \\
\hline 11 & FTR & 100 & $\mathrm{~V}$ & \\
\hline
\end{tabular}




\begin{tabular}{|c|c|c|c|c|}
\hline 12 & FTY & 100 & V & \\
\hline 13 & FTH & 90 & $\mathrm{~V}$ & \\
\hline 14 & FZI & 80 & $\mathrm{~V}$ & \\
\hline 15 & GRN & 80 & $\mathrm{~V}$ & \\
\hline 16 & HBL & 50 & & $\mathrm{~V}$ \\
\hline 17 & HNF & 80 & $\mathrm{~V}$ & \\
\hline 18 & IBR & 100 & $\mathrm{~V}$ & \\
\hline 19 & IHSN & 70 & & $\mathrm{~V}$ \\
\hline 20 & ARS & 100 & $\mathrm{~V}$ & \\
\hline 21 & KRN & 100 & $\mathrm{~V}$ & \\
\hline 22 & AQL & 90 & $\mathrm{~V}$ & \\
\hline 23 & MLW & 80 & $\mathrm{~V}$ & \\
\hline 24 & MTR & 50 & & $\mathrm{~V}$ \\
\hline 25 & MDF & 60 & & $\mathrm{~V}$ \\
\hline 26 & MHFZ & 50 & & $\mathrm{~V}$ \\
\hline 27 & MGL & 80 & $\mathrm{~V}$ & \\
\hline 28 & NBL & 50 & & $\mathrm{~V}$ \\
\hline 29 & NFL & 40 & & $\mathrm{~V}$ \\
\hline 30 & OLV & 60 & & $\mathrm{~V}$ \\
\hline 31 & RVN & 80 & $\mathrm{~V}$ & \\
\hline 32 & REYHN & 90 & $\mathrm{~V}$ & \\
\hline 33 & RHY & 60 & & $\mathrm{~V}$ \\
\hline 34 & SHVR & 70 & & $\mathrm{~V}$ \\
\hline \multirow[t]{3}{*}{35} & SHNT & 100 & $\mathrm{~V}$ & \\
\hline & JUMLAH & 2660 & & \\
\hline & RATA - RATA & 76,28 & & \\
\hline
\end{tabular}

Dari table hasil belajar siswa diatas dapat dianalisa selama guru menggunakan media model dengan metode inkuiri di peroleh nilai rata - rata 76, 28.

Table 4. Rentangan Nilai Yang Diperoleh Siswa Siklus II

\begin{tabular}{|c|c|}
\hline Nilai & Hasil Yang Diperoleh \\
\hline $0-60$ & 11 \\
\hline $61-70$ & 5 \\
\hline $71-80$ & 9 \\
\hline $81-90$ & 3 \\
\hline $91-100$ & 8 \\
\hline
\end{tabular}

\section{d. Refleksi}

Setelah penelitian selesai dilaksanakan, guru bersama teman kolaborasi yakni Ibu Zuharnelhas, S.Pd. SD berdiskusi untuk membicarakan hal - hal yang ditemukan saat observasi, baik yang positif maupun yang negative serta catatan - catatan penting yang harus disampaikan, diantaranya: Siswa belum berani memberikan pertanyaan dalam pembelajaran terhadap materi yang dipelajari. Masih banyak siswa yang belum berani memberikan jawaban dari pertanyaan yang diajukan guru. Siswa 
belum berani memberikan jawaban dari pertanyaan yang diajukan temannya. Hasil diskusi dengan teman kolaborasi akan dijadikan sebagai bahan untuk perbaikan tindakan pada siklus berikutnya.

\section{Siklus III}

a. Perencanaan

Pada tahap ini peneliti mempersiapkan perangkat pembelajaran yang terdiri dari rencana pelajaran, LKPD dan alat alat pengajaran yang mendukung.

b. Pelaksanaan

Pertemuan siklus ketiga dilaksanakan pada tanggal 30 Agustus 2019 dengan materi Gangguan Pernapasan Manusia. Pada tahap pelaksanaan terdiri dari tiga tahapan yaitu kegiatan awal, kegiatan inti dan kegiatan penutup.

c. Observasi

Data pelaksanaan tindakan penelitian diperoleh berupa nilai hasil belajar siswa. Hasil belajar ini berasal dari tes formatif yang dilakukan pada akhir kegiatan pembelajaran. Berdasarkan hasil tes siswa dianalisa pencapaian rata-rata serta persentase ketuntasan yang diperoleh pada setiap siklus. Hasil observasi pengamatan terhadap guru dan siswa dilakukan pada setiap siklus, juga menentukan keberhasilan penelitian ini. Berdasarkan hasil observasi didapat bahwa factor siswa dan guru sangat berpengaruh pada keberhasilan penelitian ini. Untuk mengetahui hasil belajar siswa setelah dilaksanakan perbaikan proses pembelajaraan, siswa mengerjakan soal tes. Berdasarkan hasil tes penulis memperoleh data siklus ketiga berupa nilai yang tergambar pada tabel berikut:

Tabel 5. Nilai Siswa Pada Siklus III

\begin{tabular}{|c|l|c|c|c|}
\hline No & \multicolumn{1}{|c|}{ Nama Siswa } & KD 3.2 & Tuntas & Tidak Tuntas \\
\hline 1 & AR & 80 & V & \\
\hline 2 & ASL & 90 & V & \\
\hline 3 & ALF & 80 & V & \\
\hline 4 & ARD & 100 & V & \\
\hline 5 & ATF & 100 & V & \\
\hline 6 & AZR & 80 & V & \\
\hline 7 & CRY & 80 & V & \\
\hline 8 & DNS & 100 & V & \\
\hline 9 & FZH & 70 & & \\
\hline 10 & FRD & 100 & V & \\
\hline 11 & FTR & 100 & V & \\
\hline 12 & FTY & 100 & V & \\
\hline 13 & FTH & 100 & V & \\
\hline 14 & FZI & 100 & V & \\
\hline 15 & GRN & 90 & V & \\
\hline 16 & HBL & 50 & & \\
\hline 17 & HNF & 80 & V & \\
\hline 18 & IBR & 100 & V & \\
\hline 19 & IHSN & 80 & V & \\
\hline & & & & \\
\hline
\end{tabular}




\begin{tabular}{|c|l|c|c|c|}
20 & ARS & 100 & $\mathrm{~V}$ & \\
\hline 21 & KRN & 100 & $\mathrm{~V}$ & \\
\hline 22 & AQL & 90 & $\mathrm{~V}$ & \\
\hline 23 & MLW & 90 & $\mathrm{~V}$ & \\
\hline 24 & MTR & 60 & & $\mathrm{~V}$ \\
\hline 25 & MDF & 80 & $\mathrm{~V}$ & \\
\hline 26 & MHFZ & 60 & & $\mathrm{~V}$ \\
\hline 27 & MGL & 90 & $\mathrm{~V}$ & \\
\hline 28 & NBL & 50 & & $\mathrm{~V}$ \\
\hline 29 & NFL & 60 & & $\mathrm{~V}$ \\
\hline 30 & OLV & 80 & $\mathrm{~V}$ & \\
\hline 31 & RVN & 90 & $\mathrm{~V}$ & \\
\hline 32 & REYHN & 90 & $\mathrm{~V}$ & \\
\hline 33 & RHY & 80 & $\mathrm{~V}$ & \\
\hline 34 & SHVR & 80 & $\mathrm{~V}$ & \\
\hline 35 & SHNT & 100 & $\mathrm{~V}$ & \\
\hline & JUMLAH & 2970 & & \\
\hline & RATA - RATA & 84 & & \\
\hline
\end{tabular}

Tabel 6. Rentangan Nilai Yang Diperoleh Siswa Siklus III

\begin{tabular}{|c|c|}
\hline Nilai & Hasil Yang Diperoleh \\
\hline $0-60$ & 5 \\
\hline $61-70$ & 1 \\
\hline $71-80$ & 10 \\
\hline $81-90$ & 7 \\
\hline $91-100$ & 12 \\
\hline
\end{tabular}

\section{d. Refleksi}

Berdasarkan hasil analisa pelaksanaan siklus ketiga yang dilaksanakan dengan pengamatan peneliti bersama teman kolaborasi yakninya Ibu Zuharnelhas, S.PD. SD bahwa pembelajaran pada siklus ketiga dapat meningkatkan hasil belajar siswa dalam menggunakan media model dapat meingkatkan hasil belajar peserta didik. Ketekunan siswa dalam menyelesaikan soal soal tes tergambar pada proses pembelajaran yang menyenangkan, sehingga siswa bekerja dalam kelompok terlihat semangat dan saling bekerjasama. Keberanian dalam mengemukakan pendapat mereka juga menambah kepercayaan diri dalam menyelesaikan soal tes dengan benar, sehingga dapat diambil kesimpulan bahwa pelaksanaan penelitian tindakan kelas pada materi Organ Pernapasan Manusia melalui media model dengan metode inkuiri di kelas V SD Negeri 04 Payakumbuh telah berhasil meningkatkan hasil belajar peseta didik.

\section{KESIMPULAN}

Berdasarkan hasil penelitian yang telah penulis lakukan, maka dapat disimpulkan: 
1. Dengan menggunakkan media model dengan metode inkuiri, hasil belajar peserta didik dalam mempelajari IPA di kelas V SD Negeri 04 Payakumbuh menjadi lebih meningkat.

2. Penggunaan media model dengan metode inkuiri dalam mempelajari IPA tentang system pernapasan manusia dapat meningkatkan hasil pembelajaran. Hal ini dapat dibuktikan dari hasil rekapitulasi nilai evaluasi belajar siswa yang semulanya 68 pada siklus 1, pada siklus 2 mengalami peningkatan menjadi 76 dan meningkat lagi menjadi 84 pada siklus ke III.

3. Penggunaan media model dengan metode inkuiri dapat mempercepat proses belajar mengajar dan membantu peserta didik dalam memahami pelajaran, sehingga hasil belajar peserta didik menjadi meningkat.

Berdasarkan hasil penelitian yang diperoleh dri penerapan media model dengan metode inkuiri pada materi IPA tentang organ pernapasan manusia, maka penulis berharap:

1. Dalam pelaksanaan pembelajaran IPA menggunakan metode inkuiri di perlukan media model sehingga memperoleh hasil yang diharapkan.

2. Sebagai guru hendaknya memiliki kreatifitas yang dapat meningkatkan inovasi untuk menumbuhkan motivasi belajar pada siswa.

\section{UCAPAN TERIMA KASIH}

Ucapan terima kasih sangat layak disampaikan untuk semua pihak yang telah membantu dalam pengerjaan artikel ini. Baik teman, dosen, kakak, dan yang lainnya. Artikel ini dapat dibuat karena adanya bantuan mereka. Semoga artikel ini dapat bermanfaaat untuk banyak pihak.

\section{REFERENSI}

Ahmad Susanto. 2013. Teori Belajar dan Pembelajaran di Sekolah Dasar. Jakarta: Kencana Prenadamedia Group.

Depdiknas .2003. Undang-undang RI No.20 tahun 2003.tentang sistem pendidikan nasional.

Strategi pembelajaran di SD, SRI ANITAH W, dkk. Penerbit universitas terbukaAbidin, Yunus. 2018.

Pembelajaran Literasi Strategi Meningkatkan Kemampuan Literasi Matematika, Sains, Membaca Dan Menulis. Jakarta: Bumi Aksara.

http://susitriyanti14320010.blogspot.com/

https://totoyulianto.wordpress.com/2013/03/02/metode-inkuiri-i-metode-pembelajaran/

http://mrizal291.blogspot.com/2010/05/model-atau-tiruan-sebagai-media.html

Http://www.rangkumanpustaka.com/2017/04/8-pengertian-ipa-menurut-para-ahli.html

https://www.zonareferensi.com/pengertian-hasil-belajar/

https://www.ruangguru.co.id/17-pengertian-dan-definisi-metode-menurut-para-ahli/

https://www.slideshare.net/sinuraeni/model-46872675

https://www.zonareferensi.com/pengertian-model-pembelajaran/ 